\title{
Comparison of the electrophoretic karyotypes and chromosomal location of ten genes in the two varieties of Cryptococcus neoformans
}

\author{
B. L. Wickes, ${ }^{1}+$ T. D. E. Moore ${ }^{2} \dagger$ and K. J. Kwon-Chung ${ }^{1}$ \\ Author for correspondence: K. J. Kwon-Chung. Tel: +1 301496 1602. Fax: +1 3014800050.
}

\footnotetext{
1 Laboratory of Clinical Investigation, National Institute of Allergy and Infectious Diseases, Bethesda, MD 20892, USA

2 Hormone Research Institute, University of California, San Francisco, San Francisco, CA 94143, USA
}

\begin{abstract}
We compared multiple isolates of the two varieties of Cryptococcus neoformans, as well as previously characterized representative isolates, for their electrophoretic karyotypes using pulsed-field electrophoresis. The two varieties could be clearly distinguished based upon the size of the smallest chromosome. The smallest chromosome for isolates of the gattii variety (serotypes B and C) was found to be $400-700 \mathrm{~kb}$ in size. The smallest chromosome for isolates of the neoformans variety was consistently found to be larger, approximately $770 \mathrm{~kb}$ in size. Isolates of the gattii variety averaged 13 chromosomes while the neoformans variety averaged 12 . The size of the Cryptococcus genome was found to be approximately 23 megabases. Isolates of C. neoformans var. neoformans tended to be more conserved than those of var. gattii with regard to gene position.
\end{abstract}

Keywords: Cryptococcus neoformans, pulsed-field electrophoresis, karyotype

\section{INTRODUCTION}

Cryptococcus neoformans is a basidiomycetous yeast capable of causing fatal infection in both normal and immunocompromised patients. This fungus can be divided into four serotypes (A, B, C and D); serotypes $A$ and D, and serotypes $B$ and $C$, have similar characteristics which facilitate the separation of the four serotypes into two varieties (Bennett et al., 1978; Dufait et al., 1987; KwonChung et al., 1982b, 1987; Polachek \& Kwon-Chung, 1980, 1986; Varma \& Kwon-Chung, 1989). Serotypes A and $\mathrm{D}$, the neoformans variety, have been associated with pigeon droppings as an environmental reservoir (KwonChung \& Bennett, 1992), although this has not been conclusively shown to be the primary ecological niche. On the other hand, serotypes B and C, the gattii variety, have been clearly shown to inhabit Eucalyptus trees as a primary reservoir (Ellis \& Pfeiffer, 1990). In the United States, C. neoformans infects between 5 and $10 \%$ of patients with AIDS (Chuck \& Sande, 1990); however, the infecting variety is almost always neoformans. In fact, world-wide, only five infections in AIDS patients have been documented to have been caused by the gattii variety

†Present address: Department of Laboratory Medicine, Box 0626, University of California, San Francisco, San Francisco, CA 94109-0626, USA.

Abbreviations: ATA, aurintricarboxylic acid; CHEF, contour-clamped homogeneous electric field.
(Kwon-Chung \& Bennett, 1992). In non-AIDS patients, the neoformans variety is also the most frequent cause of cryptococcosis, except in Southern California, where a significant number of patients are infected by the gattii variety (Bennett et al., 1977).

Although genetic manipulation (Kwon-Chung, 1975, 1976) and transformation (Edman \& Kwon-Chung, 1990) of $C$. neoformans are possible, very few genes have been characterized. Presently, there are only 15-20 cloned sequences. Therefore, the study of gene organization in this organism is still at a relatively early stage. Construction of a linkage map using classical genetic techniques, while possible, is difficult and laborious due to the lack of well-marked isolates. The use of pulsed-field gel electrophoresis has become a valuable method for elucidating sizes and numbers of chromosomes in various eukaryotic organisms. The ability to physically map genes and sequences by blotting and hybridization in place of the standard analysis of meiotic products has proven to be a valuable asset in studying gene organization. Linkage can be determined rapidly and simultaneously on a large number of isolates without the need for wellcharacterized tester strains and time-consuming genetic crosses requiring tetrad analysis. In species where meiosis does not exist, such as Candida albicans, or where products of meiotic recombination are not easily recovered, such as in some protozoa, this technique is extremely powerful. Furthermore, in organisms which possess heterogeneous 
karyotypes, the use of linkage mapping to identify certain chromosomes is a necessity since ethidium bromide staining alone can yield ambiguous results for variablysized chromosomes (Wickes et al., 1991b).

Suitable conditions for electrophoretic karyotyping of Cryptococcus neoformans have been previously reported (Perfect et al., 1989; Polachek \& Lebens, 1989; KwonChung et al., 1992a, b). However, C. neoformans frequently produces a large polysaccharide capsule which can interfere with spheroplasting or DNA isolation. As a result, karyotypes of this organism are frequently blurred or incompletely resolved, especially for the gattii variety. Additionally, $C$. neoformans has been shown to produce nucleases which can result in substantial degradation of high molecular mass DNA (Cazin et al., 1969). These factors have resulted in an inconclusive chromosome number and karyotype pattern for this organism.

There have been rapid improvements in pulsed-field electrophoresis, both in technique and in equipment, since its development in 1984 (Schwartz \& Cantor, 1984). As a result, the maximum size resolution for intact chromosomal DNA is almost 13 megabases $(\mathrm{Mb})$ (Orbach et al., 1988). In this paper, we describe an improved method for chromosomal preparation and separation of C. neoformans serotypes A, B, C and D. The karyotypes of multiple isolates of both varieties were compared, which allowed a determination of a minimal chromosoma number for each serotype, and an estimation of genome size. Cloned genes were used as hybridization probes to compare gene position for representative isolates of each serotype. We found that the chromosomal organization of these two varieties is distinct enough, in both size and gene organization, to constitute another method for: distinguishing the two varieties from one another.

\section{METHODS}

Isolates and hybridization probes. All isolates used in thi; study are displayed in Table 1 . All genes used as hybridization probes are displayed in Table 2 .

Preparation of cells for electrophoresis. Cells were prepared for electrophoresis by a modification of two earlier methods (Kwon-Chung et al., 1992b; Wickes et al., 1991b). All isolates were grown on YEPD agar ( $2 \%$ glucose, $2 \%$ peptone, $1 \%$ yeast extract, $2 \%$ agar; all w/v) for $24-72 \mathrm{~h}$ and then streaked onto MIN agar [ $6.7 \mathrm{~g}$ yeast nitrogen base without amino acids (Difco) $\mathrm{l}^{-1}, 2 \%$ glucose and $2 \%$ agar, final $\left.\mathrm{pH} 6.7\right]$ and incubated for $16-20 \mathrm{~h}$ at $30^{\circ} \mathrm{C}$.

For serotype $C$ isolates, approximately $3 \times 10^{8}$ cells were scraped off the agar surface and suspended in TEME $(100 \mathrm{mM}$ Tris, $\mathrm{pH} 8 \cdot 0 / 5 \mathrm{mM}$ EDTA/0.5\% 2-mercaptoethanol). Cells were then incubated at $30^{\circ} \mathrm{C}$ for $30 \mathrm{~min}$, pelleted, washed once with MES-sorb (20 mM MES, pH 6.0/1 M sorbitol) (Rhodes \& Kwon-Chung, 1985), and then resuspended in $150 \mu \mathrm{l}$ SCE-ATA [0.1 M sodium citrate, $\mathrm{pH} 5 \cdot 8 / 10 \mathrm{mM}$ EDTA/1 M sorbitol/ $6.0 \mathrm{mM}$ aurintricarboxylic acid (ATA) (Sigma)]. Fifty micrcılitres of spheroplasting solution $\left[45 \mathrm{mg} \mathrm{m}^{-1}\right.$ Lysing Enzymes (Trichoderma barzianum) (Sigma) $\mathrm{ml}^{-1}$ ] made up in SCE-ATA was added to the samples, which were then briefly vortexed.
Three hundred microlitres of $1.2 \%$ (w/v) low melting plug agarose (FMC Bioproducts) made up in $125 \mathrm{mM}$ EDTA, $\mathrm{pH} 7 \cdot 5$, held at $37^{\circ} \mathrm{C}$, was immediately added to the samples. Samples were vortexed briefly, and the molten plug agarose was then carefully pipetted into a 96-well microtitre plate on ice. Solidified plugs were removed to LET ( $45 \mathrm{mM}$ EDTA, $\mathrm{pH} 9 \cdot 0 / 10 \mathrm{mM}$ Tris, $\mathrm{pH} 8 \cdot 0 / 6.0 \mathrm{mM} \mathrm{ATA}$ ) and incubated at $30^{\circ} \mathrm{C}$ for $24 \mathrm{~h}$. LET was removed and replaced with NDS [45 mM EDTA, pH 9.0/10 mM Tris, pH 8.0/ 1.0\% (w/v) sarcosine $/ 2 \mathrm{mg}$ proteinase $\mathrm{K}$ (Boehringer Mannheim) $\mathrm{ml}^{-1}$ ]. Plugs were incubated at $50{ }^{\circ} \mathrm{C}$ for $24 \mathrm{~h}$ and prepared for electrophoresis as described previously (Wickes et al., 1991a).

For serotype A, D and B isolates, the TEME and MES-sorb steps were omitted. Instead, after washing in TEME, the cells were simply resuspended in $1.0 \mathrm{ml} \mathrm{SCS}(20 \mathrm{mM}$ sodium citrate, $\mathrm{pH} 5 \cdot 8 / 1 \mathrm{M}$ sorbitol) and vortexed for $5 \mathrm{~min}$. Cells were pelleted and resuspended in SCE-ATA as for serotype C. The remainder of the steps were identical to the procedure for serotype $\mathrm{C}$.

Electrophoresis. Electrophoresis was performed in a Bio-Rad CHEF DRII apparatus. Running conditions consisted of a dual

Table 1. Isolates of $C$. neoformans used in this study

\begin{tabular}{|c|c|c|c|}
\hline Variety & Serotype & Isolate & Source* \\
\hline \multirow{13}{*}{$\begin{array}{l}\text { C. neoformans } \\
\text { var. neoformans }\end{array}$} & A & NIH966 & Patient, California \\
\hline & A & NIH971 & Patient, Israel \\
\hline & A & NIH288 & Patient, Delaware \\
\hline & A & NIH386 & Patient, Iowa \\
\hline & A & NIH302 & Patient, Seattle \\
\hline & A & NIH371 & $\begin{array}{l}\text { Cuckoo droppings, } \\
\text { Thailand }\end{array}$ \\
\hline & $\mathrm{D}$ & NIH55 & Patient, Connecticut \\
\hline & $\mathrm{D}$ & NIH424 & $\begin{array}{l}\text { Pigeon droppings, } \\
\text { Denmark }\end{array}$ \\
\hline & $\mathrm{D}$ & NIH433 & $\begin{array}{l}\text { Pigeon droppings, } \\
\text { Denmark }\end{array}$ \\
\hline & $\mathrm{D}$ & $\mathrm{NIH} 430$ & $\begin{array}{l}\text { Pigeon droppings, } \\
\text { Denmark }\end{array}$ \\
\hline & $\mathrm{D}$ & NIH52 & Patient, Maryland \\
\hline & D & NIH12 & Patient, Georgia \\
\hline & $\mathrm{D}$ & B-3501 & $\begin{array}{l}\text { Progeny of } \\
\text { NIH1 } 2 \times \text { NIH433 }\end{array}$ \\
\hline \multirow{12}{*}{$\begin{array}{l}\text { C. neoformans } \\
\text { var. gattii }\end{array}$} & B & NIH184 & Patient, California \\
\hline & B & NIH189 & Patient, California \\
\hline & B & NIH198 & Patient, California \\
\hline & B & NIH76 & Patient, New Jersey \\
\hline & B & $\mathrm{NIH} 435$ & Patient, New Jersey \\
\hline & B & B-3939 & Patient, Zaire \\
\hline & C & NIH312 & Patient, California \\
\hline & C & $\mathrm{NIH} 403$ & Patient, California \\
\hline & $\mathrm{C}$ & NIH139 & Patient, California \\
\hline & $\mathrm{C}$ & NIH113 & Patient, California \\
\hline & $\mathrm{C}$ & NIH298 & Patient, California \\
\hline & $\mathrm{C}$ & NIH191 & Patient, California \\
\hline
\end{tabular}

* All isolates are from the culture collection of the Clinical Mycology Section, Laboratory of Clinical Investigation, NIAID, Bethesda, MD 20892, USA. 
Table 2. Genes used as hybridization probes for linkage mapping

\begin{tabular}{|lll|}
\hline Gene & Cloning method & \multicolumn{1}{c|}{ Source* } \\
\hline HIS3 & E. coli complementation & $\begin{array}{c}\text { T. D. E. Moore \& J. C. } \\
\text { Edman, unpublished }\end{array}$ \\
LEL:2 & $\begin{array}{l}\text { Sacch. cerevisiae } \\
\text { complementation }\end{array}$ & J. C. Edman, unpublished \\
rDNA & Heterologous probe & Restrepo \& Barbour (1989) \\
ADE1 & E. coli complementation & J. C. Edman, unpublished \\
ADE2 & E. coli complementation & J. C. Edman, unpublished \\
TS & PCR & J. C. Edman \& \\
& & U. Edman, unpublished \\
MAT\& & Difference cloning & Moore \& Edman (1992) \\
URA5 & E. coli complementation & Edman \& Kwon-Chung \\
& & (1990) \\
URA3 & E. coli complementation & J. C. Edman, unpublished \\
DHFR & E. coli complementation & M. Cao \& J. C. Edman, \\
& & unpublished \\
\hline
\end{tabular}

* Drs Moore, Edman and Cao are at the Hormone Research Institute, University of California, San Francisco, San Francisco, CA, USA.

ramped switch time beginning with a 100-200 s ramp for $16 \mathrm{~h}$ followed by a $200-300 \mathrm{~s}$ ramp for $32 \mathrm{~h}$ at $120 \mathrm{~V}$. Running buffer was $0.5 \times$ TBE $(1 \times$ TBE is $0.09 \mathrm{M}$ Tris/borate, $2 \mathrm{mM}$ EDTA, $\mathrm{pH} 8 \cdot(0)$ held constant at $12{ }^{\circ} \mathrm{C}$.

Linkage mapping and assignment of chromosome numbers. Isolates were selected for linkage mapping based on their previous importance in Cryptococcus genetics. Five isolates were run in four panels on a single 20-lane gel. After electrophoresis, the gel was blotted onto nylon filters (Nytran, Schleicher and Schuell) and baked at $80^{\circ} \mathrm{C}$ for $1 \mathrm{~h}$. Each panel was cut from the filter and hybridized with the gene of interest according to the method of Budowle \& Baechtel (1990). Filters were stripped according to the manufacturer's instructions, and reprobed with additional genes.

Chromosome numbers were assigned based on the previous format used for Candida albicans, which designates the largest chromosome as number one (Magee et al., 1988). However, the chromosome containing the rDNA repeats was given a number instead of the letter ' $R$ ' since size variability has not been determined for this chromosome in Cryptococcus neoformans as it has in Candida albicans. Sizes were determined by comparison to standard strains of Saccharomyces cerevisiae and Schizosaccharomyces pombe (Bio-Rad).

\section{RESULTS}

\section{Electrophoretic karyotypes of C. neoformans var. neoformans}

Ethidium bromide stained bands were counted as single chromosomes unless the bands stained more intensely than others in the same lane. In these instances, the bands were counted as two chromosomes unless otherwise indicated. It is possible that these bands contain more than two chromosomes; however, in the absence of quantitative instrumentation such as a densitometer, exact determination of chromosome number is subject to error. In these cases, estimates were intentionally conservative and were referred to as minimum numbers. The neoformans variety averaged 12.4 chromosomes per isolate, with a range of $9-15$. The most common number of chromosomes was found to be 12 . The gattii variety averaged 13 (a) Serotype A, var. neoformans

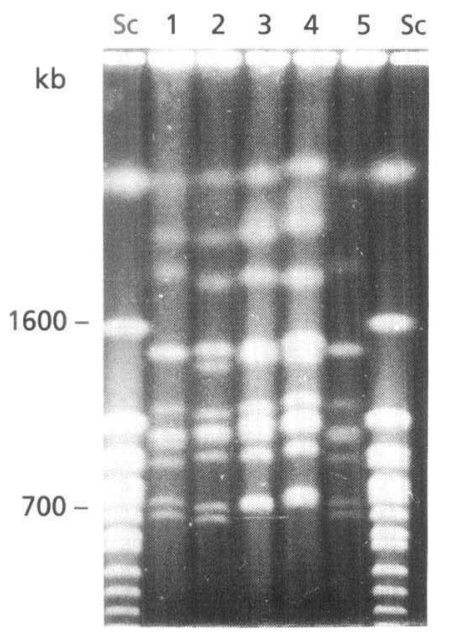

(b) Serotype D, var. neoformans

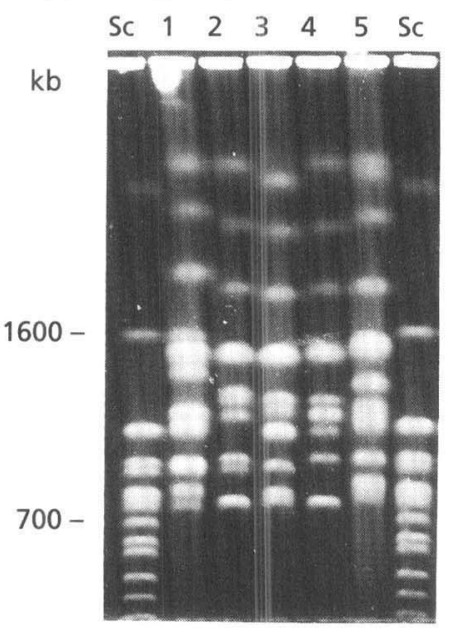

(c) Serotype B, var. gattii Sc $\begin{array}{lllll}1 & 2 & 3 & 4 & 5\end{array}$

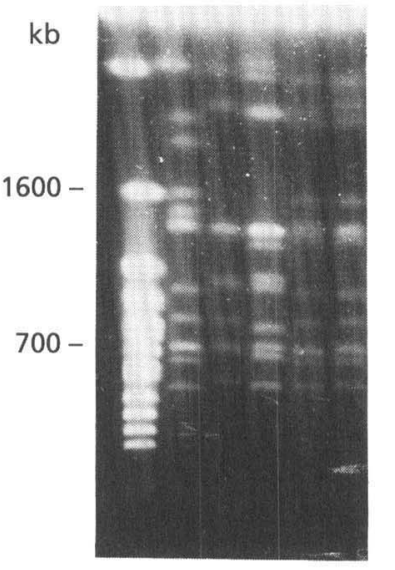

(d) Serotype C, var. gattii Sc $1 \begin{array}{lllll}1 & 2 & 3 & 4 & 5\end{array}$

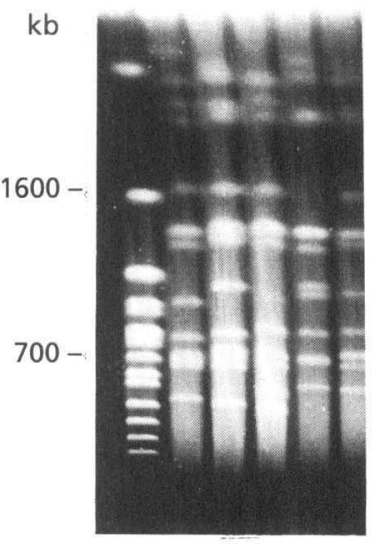

Fig. 1. CHEF panels of $C$. neoformans karyotypes. (a) Serotype A C. neoformans var. neoformans. Sc, Sacch. cerevisiae; lane 1, NIH966; lane 2, NIH971; lane 3, NIH288; lane 4, NIH386; lane 5, NIH302. (b) Serotype D C. neoformans var. neoformans. Sc, Sacch. cerevisiae; lane 1, NIH55; lane 2, NIH430; lane 3, B-3501; lane 4, NIH424; lane 5, NIH52. (c) Serotype B C. neoformans var. gattii. Sc, Sacch. cerevisiae; lane 1, NIH184; lane 2, NIH76; lane 3, NIH435; lane 4, NIH189; lane 5, NIH198. (d) Serotype C C. neoformans var. gattii. Sc, Sacch. cerevisiae; lane 1, NIH312; lane 2, NIH403; lane 3, NIH139; lane 4, NIH113; lane 5, NIH298. 
Table 3. Correlation of ethidium bromide staining bands with chromosome number in the two varieties of C. neoformans

\begin{tabular}{|c|c|c|c|c|}
\hline \multirow[t]{2}{*}{ Serotype } & \multirow[t]{2}{*}{ Isolate } & \multicolumn{3}{|c|}{ Number of: } \\
\hline & & $\begin{array}{c}\text { Ethidium } \\
\text { bromide } \\
\text { stained } \\
\text { bands }\end{array}$ & Doublets* & Chromosomes \\
\hline \multirow[t]{5}{*}{ A } & NIH966 & 10 & 2 & 12 \\
\hline & NIH971 & 11 & 2 & 13 \\
\hline & NIH288 & 10 & 2 & 12 \\
\hline & NIH386 & 11 & 2 & 13 \\
\hline & NIH302 & 8 & 2 & 10 \\
\hline \multirow[t]{5}{*}{$\mathrm{D}$} & NIH55 & 11 & 4 & 15 \\
\hline & NIH430 & 10 & 3 & 12 \\
\hline & B-3501 & 10 & 2 & 12 \\
\hline & NIH424 & 9 & 3 & 12 \\
\hline & NIH52 & 10 & 3 & 13 \\
\hline \multirow[t]{5}{*}{ B } & NIH184 & 11 & 3 & 14 \\
\hline & NIH76 & 7 & 2 & 9 \\
\hline & NIH435 & 11 & 2 & 13 \\
\hline & NIH189 & 11 & 1 & 12 \\
\hline & NIH198 & 11 & 3 & 14 \\
\hline \multirow[t]{5}{*}{$\mathrm{C}$} & $\mathrm{NIH} 312$ & 12 & 1 & 13 \\
\hline & NIH403 & 13 & 1 & 14 \\
\hline & NIH139 & 12 & 2 & 14 \\
\hline & NIH113 & 10 & 3 & 13 \\
\hline & NIH298 & 12 & 2 & 14 \\
\hline
\end{tabular}

* Bands which stained more intensely were assumed to be comprised of two chromosomes (doublets), although it is possible that there are actually more than two.

chromosomes per isolate, with a range of 9-14. The most common number of chromosomes for this variety was 14 These calculations do not include the five isolates in the panel used for linkage mapping since these are laboratory strains which have been subcultured repeatedly over a number of years.

Serotype A. Fig. 1(a) displays the karyotypes of isolates NIH966, NIH971, NIH288, NIH386 and NIH302. These isolates displayed $10,11,10,11$ and 8 ethidium bromide stained bands respectively. Based upon the staining intensity, it was concluded that these isolates possessed a minimum of $12,13,12,13$ and 10 chromosomes respectively (Table 3 ). The mean number of chromosomes for the serotype A panel was 12 , with the smallest chromosome of each isolate ranging in size from 700 to $770 \mathrm{~kb}$. The largest chromosomes were greater than $2.2 \mathrm{Mb}$ in size, with common bands observed in all isolates in the $945-1125 \mathrm{~kb}$ size range.

Serotype D. The karyotypes of representative isolates of serotype D are shown in Fig. 1(b). Isolates NIH55, NIH430, B-3501, NIH424 and NIH52 displayed 11, 10,

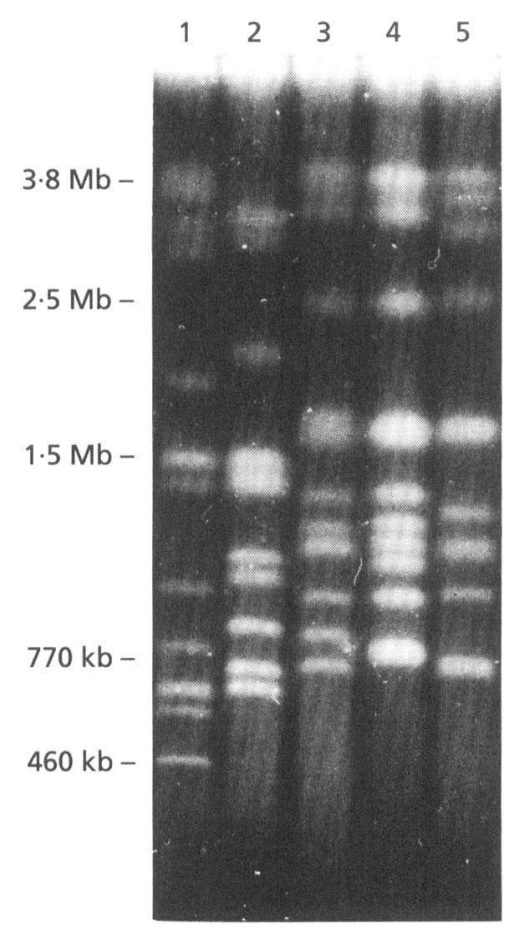

Fig. 2. CHEF panel of selected isolates used for genome size determination and linkage mapping. Lane 1, NIH191 (serotype C); lane 2, B-3939 (serotype B); lane 3, NIH12 (serotype D); lane 4, NIH433 (serotype D); lane 5, NIH371 (serotype A).

10,9 and 10 bands respectively, comprising a minimum of $15,12,12,12$ and 13 chromosomes (Table 3). The most frequent chromosome number for this panel was 12 , with the mean being $12 \cdot 8$. The smallest chromosomes were $770 \mathrm{~kb}$ in size, with the largest being greater than $2 \cdot 2 \mathrm{Mb}$ in size. All isolates had common bands approximately $1500 \mathrm{~kb}$ and $770 \mathrm{~kb}$ in size. The intense staining band in the $1500 \mathrm{~kb}$ size range was counted as three chromosomes in this case since extended separation has revealed three chromosomes in this region (Kwon-Chung et al., 1992a).

\section{Electrophoretic karyotypes of C. neoformans var. gattii}

Serotype B. The karyotypes of these isolates are shown in Fig. 1(c). The isolates used in this panel were NIH184, NIH76, NIH435, NIH189 and NIH198. These isolates displayed 11, 7, 11, 11 and 11 bands, comprising at least $14,9,13,12$ and 14 chromosomes respectively (Table 3 ). The smallest chromosome present in each of these isolates was approximately $500 \mathrm{~kb}$ in size. The largest chromosomes were greater than $2 \cdot 2 \mathrm{Mb}$ in size. The karyotypes of this group of isolates appeared to be conserved, with common bands found at 1400,1000, 850, 700 and $520 \mathrm{~kb}$. The mean number of chromosomes in this panel was $12 \cdot 4$.

Serotype C. Isolates NIH312, NIH403, NIH139, NIH113 and NIH298 displayed 12, 13, 12, 10 and 12 
(a) C. neoformans var. neoformans (serotypes A and D)

NIH12

Well
NIH433

Well

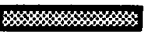

NIH371

Well

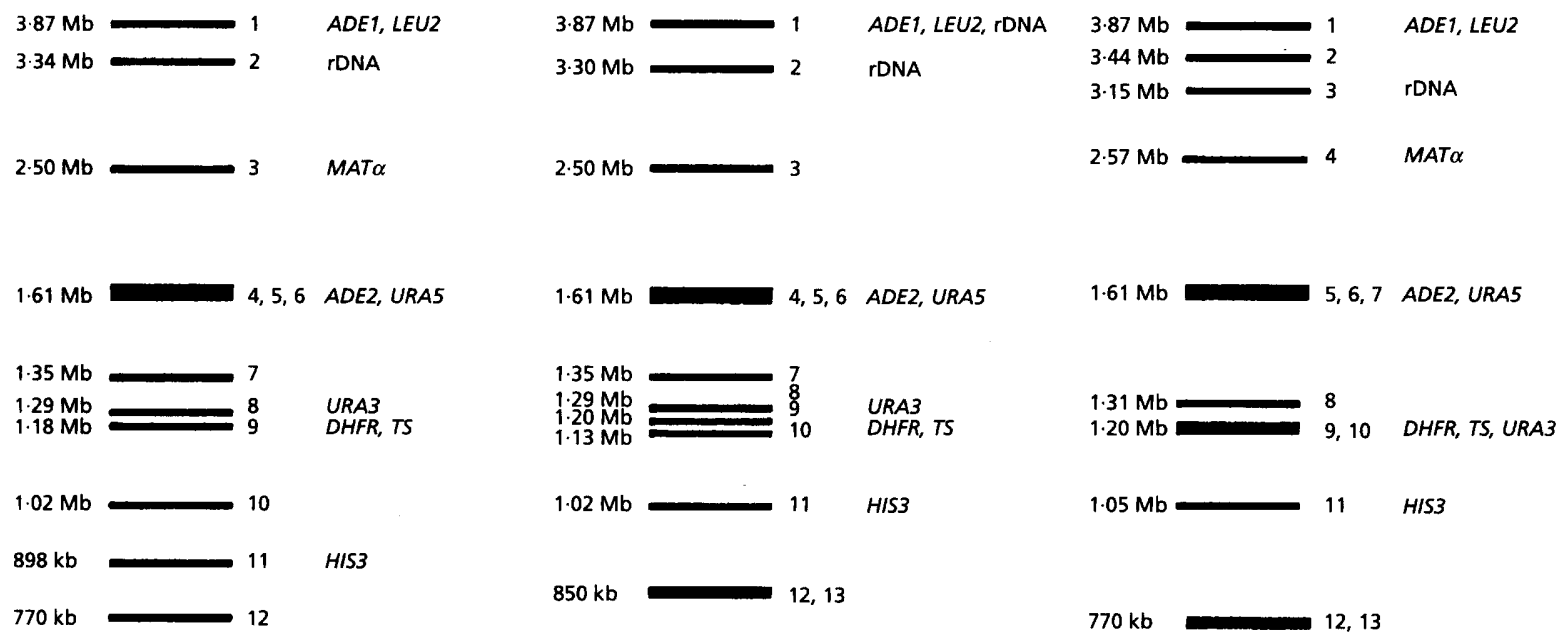

(b) C. neoformans var. gattii (serotypes B and C)

NIH191

Well

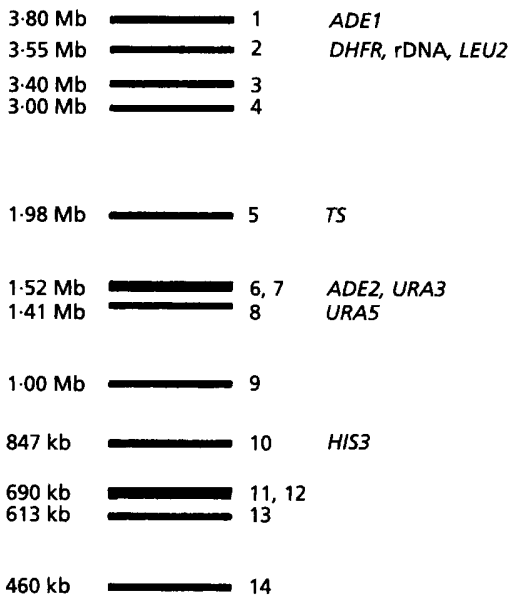

B-3939
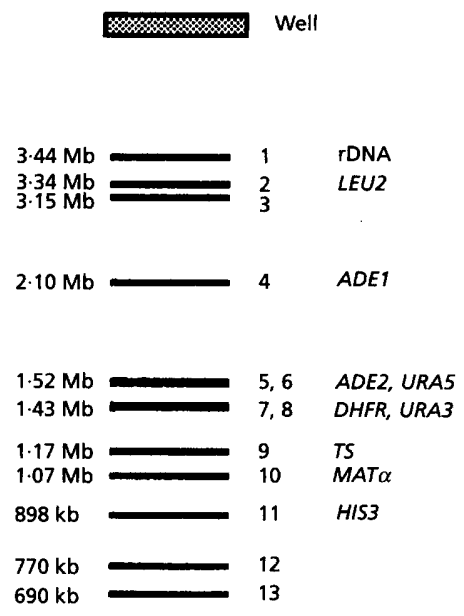

Fig. 3. Schematic diagram of (a) C. neoformans var. neoformans and (b) C. neoformans var. gattii karyotypes, chromosome sizes and gene linkage.

bands (Fig. 1d) comprising 13, 14, 14, 13 and 14 chromosomes respectively (Table 3). The smallest chromosomes displayed by this group were in the
$400-500 \mathrm{~kb}$ size range, while the largest exceeded $2 \cdot 2 \mathrm{Mb}$ in size. All isolates had common bands at 1400 and $680 \mathrm{~kb}$, with the mean number of chromosomes being 13.6. 


\section{Linkage mapping of representative isolates of $C$. neoformans}

Five isolates of $C$. neoformans were selected as representative isolates of the two varieties based upon their previous significance in $C$. neoformans genetics. They were NIH371 (serotype A, $\alpha$-mating type), NIH12 (serotype I), $\alpha$-type strain of Filobasidiella neoformans), NIH433 (serotype D, a-type complementary mating strain), B-3939 (serotype $\mathrm{B}, \alpha$-type strain of $C$. neoformans var. gattii) and NIH191 (serotype C, $a$-type strain of $F$. neoformans var. bacillispora). These isolates were electrophoresed as a single panel to facilitate comparative size measurements and linkage analysis (Fig. 2).

The DNA content in base pairs was determined for all five isolates based upon comparison of their karyotypes to two standard strains (Sacch. cerevisiae and Sch. pombe) which have well-characterized chromosome sizes. The mean genome size for all five isolates was $22881 \mathrm{~kb}$, with a range of 21048-24480 (Fig. 3a, b). The overall genome sizes of each isolate were within $90 \%$ of the mean of all five. C. neoformans var. neoformans isolate NIH371 (serotype A) had an estimated size of $24160 \mathrm{~kb}$ dispersed over 13 chromosomes. NIH433 and NIH12 (both serotype D) had genome sizes of $22190 \mathrm{~kb}$ and $21048 \mathrm{~kb}$ respectively (Fig. 3a). NIH12 had 12 chromosomes and NIH433 had 13. C. neoformans var. gattii was represented by B-3939 (serotype B) and NIH191 (serotype C). These two isolates had genome sizes of $22528 \mathrm{~kb}$ and $24480 \mathrm{~kb}$ respectively (Fig. 3b). B-3939 displayed 13 chromosomes while NIH191 displayed 14.

Analysis of gene position using labelled probes showed an interesting contrast between the two varieties. Isolates of the neoformans variety appeared to have a conserved linkage pattern with respect to gene position, as most genes were found to reside on similar-sized chromosomes for each of the three isolates (Figs 3a, 4, and 5). While this was occasionally the case for the gattii variety (Fig. 3b, Fig. 4), in other cases, gene position appeared to be heterogeneous (Fig. 5). Probing the neoformans variety with all of the available cloned genes revealed three pairs of genes which hybridized to the same or similar-sized chromosomes. They were; ADE2-URA5 (chromosomes 4-7, 1.61 Mb size range), ADE1-LEU2 (chromosome $1,3.87 \mathrm{Mb}$ size range), and DHFR-TS (chromosomes $9-10,1 \cdot 0 \mathrm{Mb}$ size range). It is not known whether this relationship holds for other linkage groups, or if it occurs in all isolates of this variety. Additionally, since so few Cryptococcus genes have been cloned, it is possible that these chromosomes are not homologous. Linkage patterns in the gattii variety tended to be less conservative, with only the $A D E 2$ and $U R A$ genes hybridizing to similar-sized chromosomes. In all isolates, the rDNA sequence hybridized to the larger $(>2 \mathrm{Mb})$ chromosomes. In multiple subclones of the same isolate, heterogeneity of the rDNA gene was not observed. However, hybridization to more than one chromosome was found for one isolate (NIH433).

The relationship of mating type and the physical presence of an $\alpha$-specific sequence was also observed. When the

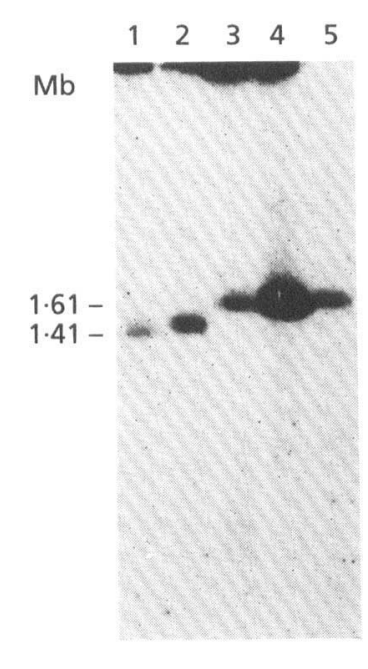

Fig. 4

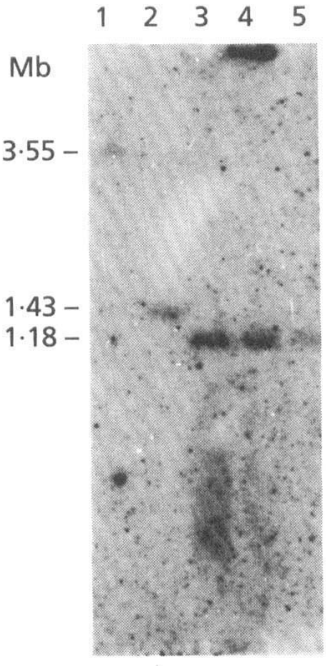

Fig. 5
Fig. 4. Hybridization of the $C$. neoformans URA5 gene to a blot of the CHEF panel displayed in Fig. 2.

Fig. 5. Hybridization of the C. neoformans DHFR gene to a blot of the CHEF panel displayed in Fig. 2.

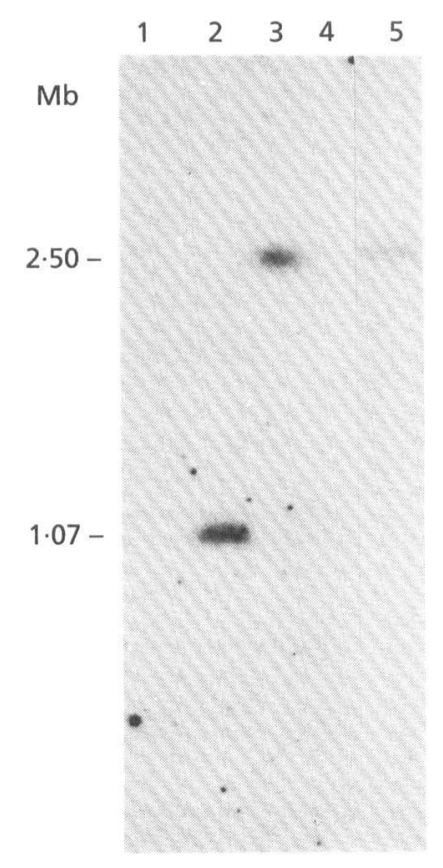

Fig. 6. Hybridization of MAT $\alpha$ to the panel in Fig. 2. This sequence hybridized to B-3939 of the gattii variety (lane 2), NIH12 (lane 3), and NIH371 (lane 5) of the neoformans variety.

$M A T \alpha$ sequence was used as a hybridization probe, only those isolates that display $M A T \alpha$ mating-type behaviour (B-3939, NIH12 and NIH371) showed a band (Fig. 6). This pattern was also observed when the sequence was hybridized to genomic digests of these isolates (data not shown). 


\section{DISCUSSION}

Previous attempts at determining the karyotype of $C$. neoformans have been adversely affected by difficulties in plug preparation. Part of the problem is the large polysaccharide capsule that this fungus produces, which can vary with growth conditions and isolate. We found that growing cultures on minimal agar and harvesting during very early exponential phase reduced the amount of capsule. For all isolates, the optimum incubation time for plug preparation encompassed a very narrow time span, usually between 16 and $20 \mathrm{~h}$ of growth. Cells that were harvested earlier than $16 \mathrm{~h}$ were very sensitive to the spheroplasting enzyme and did not yield clear karyotypes. Cells harvested later than $20 \mathrm{~h}$ tended to be much more resistant and, as a result, gave only faint ethidium bromide stained bands due to the reduced amount of DNA released from the incompletely spheroplasted cells.

Another factor which contributes to the plug preparation variability is the problem of nucleolytic degradation of chromosomal DNA. In addition to cryptococcal nucleases, the enzymes used to remove the cell wall of this yeast were found to contain significant nucleolytic activities of their own. Of the three commercially available enzymes effective for spheroplasting $C$. neoformans [Novozyme (Novo Biolabs, Bagsvaerd, Denmark), Mureinase (US Biochemical) and Lysing Enzymes (Trichoderma harzianum) (Sigma)], we found Lysing Enzymes to be the most effective. However, we found that inhibition of contaminating nucleases by ATA in preparations using this enzyme was also required. ATA has been reported to be a successful inhibitor of DNA nucleases in spheroplast transformations (Gonzalez et al., 1980; Hallick et al., 1977). When we tested the spheroplasting enzymes on naked Cryptococcus DNA, we found that the DNA was substantially degraded. ATA was able to inhibit this activity, even at very low concentrations. This is an important observation since transformation of $C$. neoformans has only been successful using electroporation (Edman \& Kwon-Chung, 1990), and not the spheroplasting method. The inclusion of a nuclease inhibitor in the transformation solution may facilitate uptake of intact DNA by spheroplasts. It has been shown that in Sacch. cerevisiae and Penicillium cbrysogenum, ATA can prevent degradation of transforming DNA during spheroplasting while not adversely affecting transformation efficiency (Ramon et al., 1986). On rare occasions isolates did not require the inhibitor; however, this generally required running a large number of lanes of the same isolate grown for various lengths of time to ascertain the narrow range of optimal spheroplasting.

A number of methods have been reported for distinguishing the two varieties of $C$. neoformans. This study has investigated differences between the two varieties at the chromosomal level. We found that the gattii variety consistently had the smaller chromosome of the two. In this variety, the smallest chromosomes were $400-700 \mathrm{~kb}$ in size, with the majority in the $500 \mathrm{~kb}$ size range. The neoformans variety generally displayed its smallest chromosomes in the $760-780 \mathrm{~kb}$ size range, regardless of serotype.
Differences were also observed in chromosome number, and were found to be variety-specific. The neoformans isolates averaged approximately 12 chromosomes per isolate while the gattii isolates averaged approximately 13 . The additional chromosomes observed in both varieties suggest that the cryptococcal genome is larger than previously believed. We now estimate the size of the Cryptococcus genome to be approximately $23 \mathrm{Mb}$. This is an important consideration for molecular analysis of $C$. neoformans since underestimation of genome size can reduce the likelihood of cloning rare sequences from genomic libraries.

The biochemical and genetic differences between the two varieties of $C$. neoformans are numerous enough to suggest that they may be diverging into separate species. This is reflected in the difficulty of obtaining fertile progeny in intervarietal crosses (gattii $\times$ neoformans). In fact, such crosses performed by Kwon-Chung et al. (1982a) resulted in viable progeny only if the parental isolates were serotypes $\mathrm{B}$ and $\mathrm{D}$. In these instances viability was low, approximately $30 \%$. This percentage may have reflected incompatible karyotypes of the parental isolates. Data from studies of the influence of participating karyotypes on spore viability in Sacch. cerevisiae are consistent with these observations. In one study, it was found that spore viability in crosses of isolates from different laboratories was decreased (Ono \& Ishino-Arao, 1988). In another study, Bidenne et al. (1992) showed that in crosses of isolates with disparate karyotypes or non-homologous linkage groups, spore viability was also greatly reduced. We have observed that two strains of the same serotype which have similar karyotypes produce a greater percentage of viable spores (data not shown) than do strains with different karyotypes. We observed serotype B and D karyotypes to be more similar than serotype $C$ and D karyotypes. This may explain why serotype $C$ isolates have not been shown to produce viable spores when crossed to serotype $\mathrm{D}$ isolates.

Linkage of the $M A T \alpha$ sequence in the two varieties is also consistent with these observations. Hybridization of $M A T \alpha$ to blots of both varieties shows that this gene is located on two different chromosomes, depending on the variety. In the rare instances of successful (viable basidiospores) intervarietal crosses, self-fertile $(\mathrm{a} / \alpha)$ progeny have been reported at an unusually high frequency (Kwon-Chung et al., 1982a). The high proportion of a $/ \alpha$ progeny may be the result of linkage of the mating type loci to different genes located on different chromosomes in the two varieties. If these genes are lost during segregation of the mating-type locus, the phenotype is lethal and the spore is non-viable. If $M A T a$ and $M A T \alpha-$ linked genes are cloned in the future, it will be interesting to see if their chromosomal locations support these observations.

In this study we have shown that the karyotypes of the two varieties of $C$. neoformans are distinct and consistent with the differences reported using other methods of classification. As the number of cloned sequences from this yeast increases, linkage mapping will provide a more 
detailed picture of gene organization in this organism. Comparison of gene organization in the two varieties using electrophoretic karyotypes has proven to be another valuable tool for studying the taxonomic relationship of these two varieties to each other.

\section{ACKNOWLEDGEMENTS}

We are grateful to Jeff Edman for his helpful comments and suggestions during the course of this study.

\section{REFERENCES}

Bennett, J. E., Kwon-Chung, K. J. \& Howard, D. H. (1977). Epidemiologic differences among serotypes of Cryptococcus neoformans. A J Epidemiol 105, 582-586.

Bennett, J. E., Kwon-Chung, K. J. \& Theodore, T. S. (1978). Biochemical differences between serotypes of Cryptococcus neoformans. Sabouraudia 16, 167-174.

Bidenne, C., Blondin, B., Dequin, S. \& Vezinhet, F. (1992). Analysis of the chromosomal DNA polymorphisms of wine strains of Saccharomyces cerevisiae. Curr Genet 22, 1-7.

Budowle, B. \& Baechtel, F. S. (1990). Modifications to improve the effectiveness of restriction fragment length polymorphism typing. Appl Theor Electrophoresis 1, 181-187.

Cazin, J., Kozel, T. R., Lupan, D. M. \& Burt, W. R. (1969). Extracellular deoxyribonuclease production by yeasts. $J$ Bacteriol 100, 760-762.

Chuck, S. L. \& Sande, M. A. (1990). Infections with Cryptococcus neoformans in the acquired immunodeficiency syndrome. $N$ Engl J Med 321, 794-799.

Dufait, R., Velhol, R. \& de Vroey, C. (1987). Rapid identification of the two varieties of Cryptococcus neoformans by D-proline assimilation. Mykosen 30, 483.

Edman, J. C. \& Kwon-Chung, K. J. (1990). Isolation of the UR A5 gene from Cryptococcus neoformans var. neoformans and its use as a selective marker for transformation. Mol Cell Biol 10, 4538-4544.

Ellis, D. H. \& Pfeiffer, T. F. (1990). Natural habitat of Cryptococcus neoformans var. gattii. J Clin Microbiol 28, 1642-1644.

Gonzalez, R. G., Haxo, R. S. \& Schleich, T. (1980). Mechanism of action of polymeric aurintricarboxylic acid, a potent inhibitor of protein-nucleic acids interactions. Biochemistry 18, 4299-4303.

Hallick, R. B., Chelm, B. K., Gray, P. W. \& Orozco, E. M. (1977). Use of aurintricarboxylic acid as an inhibitor of nucleases during nucleic acid isolation. Nucleic Acids Res 4, 3055-3064.

Kwon-Chung, K. J. (1975). A new genus, Filobasidiella, the perfect state of Cryptococcus neoformans. Mycologia 67, 1197-1200.

Kwon-Chung, K. J. (1976). A new species of Filobasidiella, the sexual state of Cryptococcus neoformans B and C serotypes. Mycologia 68, 942-946.

Kwon-Chung, K. J. \& Bennett, J. E. (1992). Cryptococcosis. In Medical Mycology, pp. 398-399. Philadelphia, PA: Lea \& Febiger.

Kwon-Chung, K. J., Bennett, J. E. \& Rhodes, J. C. (1982a). Taxonomic studies on Filobasidiella species and their anamorphs. Antonie Leeunenboek 48, 25-38.

Kwon-Chung, K. J., Polachek, I. \& Bennett, J. E. (1982b). Improved diagnostic medium for the separation of Cryptococcus neoformans var. neoformans from Cryptococcus neoformans var. gattii. J Clin Microbiol 15, $535-537$.
Kwon-Chung, K. J., Wickes, B. L., Booth, J. L., Vishniac, H. S. \& Bennett, J. E. (1987). Urease inhibition by EDTA in the two varieties of Cryptococcus neoformans. Infect Immun 55, 1751-1754.

Kwon-Chung, K. J., Edman, J. C. \& Wickes, B. L. (1992a). Genetic association of mating types and virulence in Cryptococcus neoformans. Infect Immun 60, 602-605.

Kwon-Chung, K. J., Wickes, B. L., Stockman, L., Roberts, G. D., Ellis, D. \& Howard, D. H. (1992b). Virulence, serotype, and molecular characteristics of environmental strains of Cryptococcus neoformans var. gattii. Infect Immun 60, 1869-1874.

Magee, B. B., Koltin, Y., Gorman, J. A. \& Magee, P. T. (1988). Assignment of cloned genes to seven electrophoretically separated Candida albicans chromosomes. Mol Cell Biol 8, 4721-4726.

Moore, T. D. E. \& Edman, J. C. (1992). The $\alpha$-mating type locus of Cryptococcus neoformans contains a peptide pheromone gene. Mol Cell Biol 13, 1962-1970.

Ono, B. \& Ishino-Arao, Y. (1988). The inheritance of chromosome length polymorphisms in Saccbaromyces cerevisiae. Curr Genet 14, 413-418.

Orbach, M. J., Volrath, D., Davis, R. W. \& Yanofsky, C. (1988). An electrophoretic karyotype for Neurospora crassa. Mol Cell Biol 8, 1469-1473.

Perfect, J. R., Magee, B. B. \& Magee, P. T. (1989). Separation of chromosomes of Cryptococcus neoformans by pulsed field electrophoresis. Infect Immun 57, 2624-2627.

Polachek, I. \& Lebens, G. A. (1989). Electrophoretic karyotype of the pathogenic yeast Cryptocococcus neoformans. J Gen Microbiol 135, 65-67.

Polachek, I. \& Kwon-Chung, K. J. (1980). Creatinine metabolism in Cryptococcus neoformans and Cryptococcus bacillisporus. J Bacteriol 142, 15-20.

Polachek, I. \& Kwon-Chung, K. J. (1986). Canavanine resistance in Cryptococcus neoformans. Antimicrob Agents Chemother 26, 463-473.

Ramon, D., Ferrer, S., Vicente, E. \& Uruburu, F. (1986). Aurintricarboxylic acid as a nuclease inhibitor in fungal protoplasts. FEMS Microbiol Lett 36, 9-13.

Restrepo, B. I. \& Barbour, A. G. (1989). Cloning of $18 \mathrm{~S}$ and $25 \mathrm{~S}$ rDNAs from the pathogenic fungus Cryptococcus neoformans. $J$ Bacteriol 171, 596-600.

Rhodes, J. C. \& Kwon-Chung, K. J. (1985). Production and regeneration of spheroplasts from Cryptococcus. Sabouraudia 23, $77-80$.

Schwartz, D. C. \& Cantor, G. R. (1984). Separation of yeast chromosome-sized pieces of DNA by pulsed field gradient gel electrophoresis. Cell 37, 67-75.

Varma, A. \& Kwon-Chung, K. J. (1989). Restriction fragment polymorphism in mitochondrial DNA of Cryptococcus neoformans. $J$ Gen Microbiol 135, 3353-3362.

Wickes, B. L., Golin, J. E. \& Kwon-Chung, K. J. (1991a). Chromosomal rearrangement in Candida stellatoidea results in a positive effect on phenotype. Infect Immun 59, 1762-1771.

Wickes, B. L., Staudinger, J., Magee, B. B., Kwon-Chung, K. J., Magee, P. T. \& Scherer, S. (1991b). Physical and genetic mapping of Candida albicans: several genes previously assigned to chromosome 1 map to chromosome $\mathrm{R}$, the rDNA containing linkage group. Infect Immun 59, 2408-2484.

Received 7 June 1993; revised 16 September 1993; accepted 30 September 1993. 